\title{
SIMULATION OF THERMAL CONVERSION OF SOLID FUEL BY THE DISCRETE PARTICLE METHOD
}

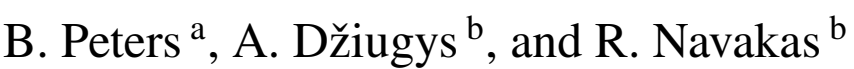 \\ ${ }^{a}$ Faculté des Sciences, de la Technologie et de la Communication, Université du Luxembourg, Campus Kirchberg, 6, rue \\ Coudenhove-Kalergi, L-1359 Luxembourg \\ E-mail: bernhard.peters@uni.lu \\ ${ }^{\mathrm{b}}$ Laboratory of Combustion Processes, Lithuanian Energy Institute, Breslaujos 3, LT-44403 Kaunas, Lithuania \\ E-mail: dziugys@mail.lei.lt
}

Received 15 April 2011; revised 26 May 2011; accepted 21 June 2011

\begin{abstract}
We introduce the discrete particle method (DPM) that derives from the discrete element method (DEM). This is an advanced numerical simulation tool that takes into account both motion and chemical conversion of granular material, such as coal or biomass, in furnaces in conjunction with computational fluid dynamics (CFD). However, predictions of solely motion or conversion in a decoupled mode are also applicable. The DPM uses object oriented computational techniques that support objects representing three-dimensional particles of various shapes, size, and physical properties of particle material. This makes DPM a highly versatile tool in dealing with a variety of problems related to different industrial applications of granular matter. A review of literature concerning different approaches to mass and heat transfer in packed beds is presented.
\end{abstract}

Keywords: dicrete particle method (DPM), numerical modelling, combustion, moving bed, forward acting grate

PACS: 88.20.jj, 47.70.Pq, 07.05.Tp, 45.10.-b, 46.15.-x, 45.70.Mg

\section{Introduction}

An increasing environmental awareness demands reductions in energy consumption by better efficiency and a sustainable treatment of energy sources. In order to comply with a sustainable approach, a deeper knowledge of energy conversion or energy producing processes has to be gained which is addressed by the discrete particle method (DPM) introduced in the present work. Relevant areas of application are furnaces for wood combustion, blast furnaces for steel production, fluidised beds, cement industry, or predictions of emissions concerning air quality. Each of these applications represent complex processes involving various aspects of thermodynamics, fluid dynamics, chemistry, and physics. Hence, the DPM is an advanced multiphysics and numerical simulation tool that deals with both motion and chemical conversion of particulate material in conjunction with computational fluid dynamics (CFD). However, predictions of solely motion or conversion in a decoupled mode are also applicable.

The solid fuel consists of a number of solid particles arranged on a grate (fixed or moving) of a combustor; the set of fuel particles is referred to as a packed bed.
Thermal conversion of solid fuel is a complex interaction of fluid flow, heat and mass transfer within both moving and fixed beds of fuel particles. An accurate description of fluid flow through packed beds and its mass and heat transfer is important to the design of packed bed reactors. The solution of this problem requires an extensive knowledge of heat transfer and mass transfer characteristics within the bed. Although heat and mass transfer in packed beds and to the fluid are widely applied in various domains, it is largely based on empirical correlations. The latter often describe heat transfer insufficiently, and therefore, require more intensive investigations.

Experiments with a high resolution tend to be very expensive, while the costs of numerical approaches even including a large degree of details decrease. Thus, numerical models including CFD have proven to be a reliable tool to evaluate the interaction of fluid and packed beds. It allows extracting a deeper knowledge of heat and mass transfer within complex geometries and leads to better understanding of the phenomena involved. Among them are the different modes of heat transfer, namely conduction, convection, and radiation. 


\section{A short review of heat transfer in granular systems}

\subsection{Modes of heat transfer}

\subsubsection{Conductive heat transfer}

Conductive heat transfer in granular systems may be described simply by conduction between the particles in contact and no continuous phase is required. Smirnov et al. [1, 2] investigated experimentally radial heat transfer between a packed bed and walls. The flow of heat in a rotating tumbler containing granular material was studied by Figueroa et al. [3] dependent on the crosssectional shape of the tumbler, degree of filling, and rotational speed. The approach of thermal particle dynamics (TPD) was employed, which assumes that the temperature gradients propagate only within the nearest neighbours of any given particle during a single time step. The Péclet number for granular systems was defined as a ratio of the mixing and thermal diffusion rates. In order to quantify the impact of mixing on the overall rate of heat transfer, the "apparent heat transfer coefficient" was introduced, relating the wall temperature and the average temperature in the granular bed. It has been shown that increasing mixing rates might decrease the rate of heating of the granular bed, because at higher mixing rates the contact time between the particles is reduced.

\subsubsection{Convective heat transfer}

Convective heat transfer is distinguished in free and forced convection, whereby forced convection, in particular in engineering applications, has a higher importance.

Free convection Laguerre et al. [4] investigated two modelling approaches of transient heat transfer due to free convection in a packed bed of spheres. The first approach employed computational fluid dynamics software which directly solves the Navier-Stokes equations and the local energy equations in the fluid and solid phase. The entire geometry, including both fluid and solid phases, is meshed into elementary cells for this purpose. Additionally, this model included radiation between the solid surfaces. In the second approach, the methods developed for porous media and packed beds were applied, in particular, the DarcyForchheimer equation, coupled with continuity equation:

$$
\nabla \cdot \boldsymbol{u}=0
$$

$$
\nabla p=-C_{1}^{*} \frac{\mu}{D^{2}} \boldsymbol{u}-C_{2}^{*} \frac{\varrho}{D}|\boldsymbol{u}| \boldsymbol{u}-\varrho_{\mathrm{m}} \beta\left(T_{\text {air }}-T_{\mathrm{m}}\right) \boldsymbol{g},
$$

where $\varrho_{\mathrm{m}}$ is the air density at the mean temperature $T_{\mathrm{m}}$, $\beta$ is the thermal expansion coefficient, $\varrho$ and $\mu$ are air density and viscosity coefficients, $\boldsymbol{u}$ is the velocity vector, $\boldsymbol{g}$ is the gravity acceleration vector, and $C_{1}^{*}, C_{2}^{*}$ are the Darcy-Forchheimer coefficients. The radial heat conduction inside the particles is described by

$$
\varrho_{\mathrm{p}} C_{p_{\mathrm{p}}} \frac{\partial T_{\mathrm{p}}}{\partial t}=\frac{1}{r^{n}} \frac{\partial}{\partial r}\left(k_{\mathrm{p}} r^{n} \frac{\partial T_{\mathrm{p}}}{\partial r}\right),
$$

where $n$ is the particle form-factor $(n=1$ for long cylinders, $n=2$ for spheres), $\varrho_{\mathrm{p}}, C_{p_{\mathrm{p}}}, k_{\mathrm{p}}$ are particle density, heat capacity at constant pressure, and thermal conductivity, respectively, $T_{\mathrm{p}}$ is the particle temperature. The heat balance on the surface of the particles per unit volume of the packed bed is given by

$$
a_{\nu} k_{\mathrm{p}}\left(\frac{\partial T_{\mathrm{p}}}{\partial r}\right)_{r=R}=a_{\nu} h\left(T_{\mathrm{air}}-T_{\mathrm{p}, s}\right)+k_{\mathrm{eq}} \nabla^{2} T_{\mathrm{p}, s},
$$

where $a_{\nu}$ is the air-particle interface area per unit volume of the packed bed. The first term in (4) describes the conductive heat flux from the particle surface towards the centre, the second term is the convective heat exchange between the particle and the air, with heat transfer coefficient $h$ obtained from correlations between Nusselt and Reynolds numbers in packed beds, and the third term takes into account the conductive and radiative exchanges between the particle surfaces. The equivalent thermal conductivity $k_{\text {eq }}$ depends on fluid and solid thermal conductivities, particle arrangement, and surface emissivity. Similarly, the convective heat balance for the fluid is expressed as

$$
\varepsilon \varrho_{\mathrm{f}} C_{p_{\mathrm{f}}} \frac{\partial T_{\text {air }}}{\partial t}+\nabla \cdot\left(\varrho_{\mathrm{m}} C_{p} T_{\text {air }} \boldsymbol{u}\right)=a_{\nu} h\left(T_{\mathrm{p}, s}-T_{\text {air }}\right) .
$$

The first term corresponding to the thermal inertia was neglected because the thermal characteristic time for air is much higher than that for the particles.

The heat transfer model, based on a dispersed particle approach, takes into account air-particle convection, conduction and radiation between particles. The free convection is taken into account using the Boussinesq approximation (the buoyancy term in (2)). It is assumed that the temperature distribution inside the particles is spherically symmetric, therefore, a onedimensional model is used, describing the temperature distribution in the radial direction. The numerical results obtained including particle temperature using the two approaches were in good agreement with 
the experimental values of air for a free convection configuration.

Forced convection Radial and axial heat transfer between walls and a packed bed of spheres of diameter $d=3.8 \mathrm{~cm}$ with an air flow of rather low velocity was studied by Laguerre et al. [5]. Their approach distinguishes fluid and solid phase temperatures to characterize the heat transfer between both wall and air as well as between a wall and adjacent particles. It was found that the air velocity and the arrangement of particles along the wall influence the convective heat transfer in the voids near the wall and particles. However, the effect of temperature difference between the wall and the air is negligible.

Swailes and Potts [6] developed and analysed models for transient forced convection of a heated gas through granular porous media of low thermal conductivity, based on the following equations:

$$
\begin{gathered}
\frac{\partial}{\partial t} \varrho+\frac{\partial}{\partial x} \varrho u=0 \\
\frac{\partial}{\partial t} \varrho u+\frac{\partial}{\partial x}\left(\varrho u^{2}+\varrho R T\right)=-\left(\alpha C_{1} u+\alpha^{2} C_{2} \varrho u^{2}\right) \\
\frac{\partial}{\partial t}(c-R) T+\frac{\partial}{\partial x} \varrho(c-R) T u
\end{gathered}
$$

where $\alpha$ is the constant bed porosity, $R$ is the universal gas constant for the air, $c$ is the specific heat capacity, $C_{1}$ and $C_{2}$ are the Darcy-Forchheimer (drag) coefficients given by

$$
C_{1}=\frac{\mu}{K}, C_{2}=\frac{F}{\sqrt{K}},
$$

where $\mu$ is the gas viscosity, and $K$ and $F$ are permeability and Forchheimer coefficients, respectively, modelled in the form

$$
K=\frac{d^{2} \alpha^{3}}{150(1-\alpha)^{2}}, F=\frac{1.75}{\sqrt{150 \alpha^{3}}},
$$

where $d$ is the particle diameter. The heat flux $\Phi$ per unit volume from gas to solid phase can be written as

$$
\Phi=\left.\frac{3(1-\alpha)}{R} \lambda \frac{\partial \theta}{\partial r}\right|_{r=R},
$$

where $\lambda$ is the heat transfer coefficient for the solid phase, $\theta$ is the internal temperature inside the solid particle, and $R$ is the particle radius.

Venugopal et al. [7] experimentally investigated the potential of a simple and inexpensive porous inserts developed specifically for augmenting heat transfer from the heated wall of a vertical duct under forced flow conditions. The characteristic features of the porous medium model on the hydrodynamic and heat transfer behaviour have also been investigated. They developed a new correlation method for the Nusselt number that does not require any information from hydrodynamic studies. Over the range of parameters considered, the largest increase of 4.52 times in the average Nusselt number was observed in a porous material of porosity of 0.85 compared to that in an unobstructed flow.

\subsubsection{Radiative heat transfer}

The design of efficient burners, furnaces, and other systems based on combustion requires accurate prediction of heat transfer rates. Conductive and convective heat transfer rates are generally proportional to the temperature difference, while radiative heat transfer is proportional to the fourth power of the temperature. Therefore, an accurate evaluation of thermal radiation is very important in combustion applications, where the total heat transfer may mainly be due to thermal radiation. It may amount up to $40 \%$ in fluidized bed combustion as estimated by Tien et al. [8] and 90\% in large-scale coal combustion chambers evaluated by Manickavasagam and Menguc [9].

Hence, prediction of the heat transfer process in a typical high-temperature energy conversion device such as an internal combustion engine includes, apart from equations for momentum, turbulence, and mass, also one general equation for energy conservation, incorporating all three modes of heat transfer. It comprises convection, conduction, and radiation where the radiative heat transfer part represents an integrodifferential equation that deals with seven independent variables:

- time,

- three space coordinates,

- two angles describing the direction of travelling photons,

- frequency of radiation,

while conduction and convection involve a maximum of four independent variables, namely time and three space coordinates. The general equation for energy conservation for moving compressible fluid is expressed as [10]

$$
\begin{aligned}
& \varrho c_{v}\left(\frac{\partial T}{\partial t}+\boldsymbol{v} \cdot \nabla T\right)= \\
& -\nabla \cdot\left(-k \nabla T+\boldsymbol{q}_{\mathrm{R}}\right)-p \nabla \cdot \boldsymbol{v}+\mu \Phi+\dot{Q}^{\prime \prime \prime},
\end{aligned}
$$


where $\varrho$ is the fluid density, $c_{v}$ is the fluid heat capacity at constant volume, $T$ is temperature, $\boldsymbol{v}$ is the velocity vector, $\boldsymbol{q}_{\mathrm{R}}$ is the heat flux vector due to radiation, $p$ is pressure, $\mu$ is dynamic viscosity, $\Phi$ is dissipation function, $Q^{\prime \prime \prime}$ is heat production per unit volume. The terms on the left-hand side of (12) describe the energy transfer due to convection, and the terms on the right-hand side describe, respectively, energy transfer due to heat conduction, radiation, pressure work, viscous dissipation, and the last term on the right-hand side is the source term due to internal generation. The radiative part is given by

$$
\nabla \cdot \boldsymbol{q}_{\mathrm{R}}=\kappa_{\lambda}\left[4 \pi i_{\lambda b}\left(\tau_{\lambda}\right)-G\left(\tau_{\lambda}\right)\right],
$$

where the blackbody intensity $i_{\lambda b}$ is the Planck's intensity function, $\kappa_{\lambda}$ is the local linear spectral absorption coefficient of the medium, and the incident radiation $G$ is expressed as

$$
G\left(\tau_{\lambda}\right)=\int_{\phi=0}^{2 \pi} \int_{\theta=0}^{\pi} i\left(\tau_{\lambda}, \theta, \phi\right) \sin \theta \mathrm{d} \theta \mathrm{d} \phi,
$$

where the intensity of radiation at any optical depth $\tau_{\lambda}$ is given by

$$
\begin{aligned}
& i\left(\tau_{\lambda}, \theta, \phi\right)=i(0, \theta, \phi) \exp \left(-\tau_{\lambda}\right) \\
& +\int_{0}^{\tau_{\lambda}} S\left(\tau_{\lambda}^{\prime}, \theta^{\prime}, \phi^{\prime}\right) \exp \left[-\left(\tau_{\lambda}-\tau_{\lambda}^{\prime}\right)\right] \mathrm{d} \tau_{\lambda}^{\prime},
\end{aligned}
$$

where $\theta$ and $\phi$ are the zenith and azimuthal angles of radiation propagation direction. The source function in the above is given by

$$
\begin{aligned}
& S\left(\tau_{\lambda}, \theta, \phi\right)=(1-\omega) i_{\lambda b}\left(\tau_{\lambda}\right) \\
& +\left(\frac{\omega}{4 \pi}\right) \int_{\phi^{\prime}=0}^{2 \pi} \int_{\theta^{\prime}=0}^{\pi} i\left(\tau_{\lambda}, \theta^{\prime}, \phi^{\prime}\right) \\
& \times p\left[\left(\theta^{\prime}, \phi^{\prime}\right) \rightarrow(\theta, \phi)\right] \sin \theta^{\prime} \mathrm{d} \theta^{\prime} \mathrm{d} \phi^{\prime},
\end{aligned}
$$

where $\omega_{\lambda}=\sigma_{\lambda s} /\left(\kappa_{\lambda}+\sigma_{\lambda s}\right)$ is the single scattering albedo, $\sigma_{\lambda \mathrm{s}}$ is the scattering coefficient, and $p\left[\left(\theta^{\prime}, \phi^{\prime}\right) \rightarrow(\theta, \phi)\right]$ is the anisotropic scattering phase function, representing the probability distribution of the energy scattered into the direction $(\theta, \phi)$ from the rays traversing the elemental volume from all the other directions $\left(\theta^{\prime}, \phi^{\prime}\right)$.

A solution of the integro-differential equation for radiation in general is extremely complicated and may be obtained only by efficient and cost-effective models that could predict radiative heat transfer rates with required accuracy as stated by Mishra and Prasad [10]. An extensive review of methods to model radiative heat transfer was carried out in [10]. Its authors have concluded that no single radiation model can be regarded as the best: the selection of the model depends upon the computing facility and desired accuracy of the result for any given problem.

Furthermore, despite the fact that radiation remains the dominant mode of heat transfer, the conduction and convection also have to be considered to evaluate the total heat transfer rate. Therefore the variation in radiative heat transfer in a packed bed as a function of the solid conductivity is of critical importance and deserves considerable attention as pointed out by Kaviany and Singh [11].

\subsection{Fluid flow through packed beds}

Flow of a fluid through a packed bed may be treated by two approaches. In a direct simulation approach the fluid flow is resolved through the void space between particles. A more general approach approximates fluid flow through the packed bed as flow through porous media. Both approaches are classified coarsely in the so called two-phase (two-equations) and single(homogeneous) phase (one-equation) models.

\subsubsection{One-phase (homogeneous) models}

This class of models relies on an averaging process over the solid and gaseous phase and therefore may be most easily treated by a CFD approach expanding into several dimensions. An additional parameter that influences the heat transfer in a packed bed is the ratio of thermal capacity of the packed bed and the fluid flow in the void space. If thermal capacity of the fluid is high as compared to a packed bed, a rather homogeneous temperature profile develops, as shown by measurements of Thoméo and Grace [12].

Fanaei and Vaziri [13] predicted heat transfer in a bio-reactor by a simple model that excluded mixing, as it would influence negatively the bio-material in the reactor. The bio-reactor consists of a bed of substrate supported on a perforated base plate through which saturated air containing water vapour is blown, and the reactor geometry is cylindrical. A "lumped" model neglected spatial variations of temperature, whereas a distributed model includes the axial dependence. These models are expressed, respectively, as follows, 
including the metabolic heat generation, convective and evaporative heat removal:

$$
\begin{aligned}
& \varrho_{\mathrm{b}} C_{p \mathrm{~b}} \frac{\partial T}{\partial t}= \\
& \varrho_{\mathrm{s}}(1-\varepsilon) Y_{Q} \frac{\mathrm{d} X}{\mathrm{~d} t}+\left(\varrho_{\mathrm{a}} C_{p \mathrm{a}}+f \lambda\right) \frac{V_{z}}{Z}\left(T_{\mathrm{a}}-T\right), \quad(17) \\
& \varrho_{\mathrm{b}} C_{p \mathrm{~b}} \frac{\partial T}{\partial t}= \\
& \varrho_{\mathrm{s}}(1-\varepsilon) Y_{Q} \frac{\mathrm{d} X}{\mathrm{~d} t}-\varrho_{\mathrm{a}} V_{z}\left(C_{p \mathrm{a}}+f \lambda\right) \frac{\partial T}{\partial z}+k_{\mathrm{b}} \frac{\partial^{2} T}{\partial z^{2}},
\end{aligned}
$$

where $C_{p \mathrm{~b}}$ and $C_{p \mathrm{a}}$ are the heat capacities of packed bed and air, $\varrho_{\mathrm{b}}, \varrho_{\mathrm{a}}, \varrho_{\mathrm{s}}$ are the densities of the packed bed, air, and substrate, respectively, $Y_{Q}$ is the metabolic heat yield coefficient, $X$ is the fraction of biomass in the packed bed, $V_{z}$ is the superficial velocity of air, $\varepsilon$ is the void fraction in the bed, $Z$ is the bed height, $T_{\mathrm{a}}$ is the air temperature at the inlet, $f$ is the water carrying capacity of air, $\lambda$ is the latent heat of evaporation of water, $k_{\mathrm{b}}$ is the thermal conductivity of the bed. Both models were employed to predict the growth of biomass in a reactor.

Moreira et al. [14] investigated the heat transfer in packed beds by five pseudo-homogeneous models. The models do not make distinction between different phases due to the difficulty of measuring temperatures of fluids and particles separately. Pseudo-homogeneous models are described by the following differential energy conservation equation:

$$
\left(G c_{p_{\mathrm{g}}}+L c_{p_{1}}\right) \frac{\partial T}{\partial z}=k_{r}\left[\frac{1}{r} \frac{\partial}{\partial r}\left(r \frac{\partial T}{\partial r}\right)\right]+k_{a} \frac{\partial^{2} T}{\partial z^{2}},
$$

where $G, L, c_{p_{\mathrm{g}}}, c_{p_{1}}, k_{r}, k_{a}$ are the superficial gas and liquid flow rates, gas and liquid heat capacities, effective radial and axial thermal conductivities, respectively. Different models differ in boundary conditions, inclusion or exclusion of axial thermal conductivity, and treatment of the wall heat transfer coefficient. The experimental set-up described in [14] consisted of a cylindrical column (diameter $5 \mathrm{~cm}$, length $80 \mathrm{~cm}$ ), filled with glass spheres (sizes between 1.9 and $4.4 \mathrm{~mm}$ ), through which air and water streamed. A comparison between measurements and predictions yielded good agreement.

A lot of studies rely on the radial effective heat conductivity $\lambda_{\text {eff }}$ and the heat transfer coefficient at the wall $\alpha_{\mathrm{w}}$ in packed beds to describe heat transfer as employed by Zehner [15], Hennecke and Schlünder [16],
Zehner and Schlünder [17], Lerou and Froment [18], Bauer [19], Dixon and Cresswell [20], Hofmann [21], and Wellauer et al. [22]. A more detailed review may be found in the articles of Westerterp et al. [23] and Tsotsas and Martin [24]. Such an approach requires thermal equilibrium between the two phases of a packed bed and is referred to as the one-equation model. Regin et al. [25] applied a one-equation model to predict the dynamic behaviour during charging and discharging of a packed bed latent heat thermal energy storage system. The packed bed consisted of spherical capsules filled with paraffin wax. They found that a solidification period is longer than a melting period due to a reduced heat transfer during solidification. Furthermore, charging and discharging rates are significantly higher for the capsule of smaller radius compared to those of larger radius.

In order to apply CFD-derived methods (in particular - differential conservation equations in space and time) for analysis of packed beds, relevant variables such as temperature, velocity, or species concentrations are averaged over the heterogeneous structure of a packed bed as employed by de Souza et al. [26], Whitaker et al. [27-29], and Quintard and Whitaker [30-34]. However, measurements of fluid flow velocity above a packed bed carried out by Negrini et al. [35] demonstrated clearly that the applicability of continuum mechanic approaches depends strongly on the ratio of the overall packed bed size to particle dimensions $\left(D / d_{\mathrm{p}}\right)$. They claimed that correlations including conservation of mass as employed by Fahien and Stankovic [36], Schwartz and Smith [37], Vortmeyer and Schuster [38], and Mueller [39] predict the velocity distribution adequately for high $D / d_{\mathrm{p}}$ ratios, although their measurements and predictions still deviated considerably. For low $D / d_{\mathrm{p}}$ ratios, the flow behaviour is determined by the anisotropic structure of the porous matrix, which leads to a rather discontinuous variation of the velocity field. This is confirmed by Benenati and Brosilow [40], Haughey and Beveridge [41], Zotin [42], Govindarao and Froment [43], Dixon [44], Mueller [39], and Zou and $\mathrm{Yu}$ [45], who investigated the void distribution in packed beds.

Winterberg et al. [46] reviewed experiments with spherical particles and derived a simple and consistent set of coefficients based on uneven flow distributions and wall heat conduction model. Distribution of both flow and porosity has been approximated by the extended Brinkmann equation and an exponential expression according to Giese et al. [47, 48]. Heat and mass transport were described by transient and 
two-dimensional differential conservation equations in cylindrical coordinates in which the relations for the transport coefficients were derived to fit the measurements. These relationships were reported to be independent of the bed to particle diameter ratio and applicable to packed beds with chemical reactions.

Liu et al. [49] undertook a similar approach based on transient and two-dimensional differential conservation equations for a porous media with evaporative cooling whereby transport properties were described by empirical correlations for respective phases. Thus, they were able to investigate the influence of diffusive motion of vapour on transport of mass, momentum, and energy.

Vortmeyer [50] investigated the importance of an uneven flow distribution in the vicinity of wall of porous reactors. Due to a higher porosity in the vicinity of the wall, the velocity increases from the non-slip condition at the wall to a maximum value until it decreases and levels out to an average value toward the centre of a packed bed as compared to a plug flow profile. Thus, he emphasizes that these wall effects may have a pronounced effect on the overall transfer conditions.

Polesek-Karczewska [51] measured the temperature distribution of a heated packed bed of different materials. Furthermore, they correlated the experimental data with theoretical and numerical approaches for a homogeneous phase model. They have concluded that the value of conductivity determined for non-homogeneous materials appears to be higher than the effective thermal conductivity determined by widely used formulae from the literature under steady state conditions.

Smirnov et al. [1, 2] carried out a study for radial heat transfer in tubular packed beds consisting of cylindrical beds formed of spheres, cylinders, and Rashig rings under steady state conditions. They aimed at determining heat transfer parameters for the standard dispersion model (SDM). As a conclusion the radial thermal conductivity for all cylindrical particles with arbitrary number and form of the channels is described by one formula with constant parameters.

\subsubsection{Two-phase (heterogeneous) models}

The homogeneous phase models of the previous section rely on thermal equilibrium between the phases considered. However, without thermal equilibrium the thermal transport in each phase and the transfer between them has to be considered as confirmed by Vortmeyer [52], Schlünder [53], Vortmeyer [52], Froment and Bischoff [54], Pereira Duarte et al. [55], and Glatzmaier and Ramirez [56]. A two-equation approach was also applied by Fourie and Du Plessis [57], who derived energy conservation equations for each phase by volume averaging; these equations are as follows:

$$
\begin{aligned}
& \varrho_{\mathrm{s}} c_{p, \mathrm{~s}} \frac{\partial\langle T\rangle_{\mathrm{s}}}{\partial t}=\nabla \cdot\left(\boldsymbol{k}_{\mathrm{ss}} \cdot \nabla\langle T\rangle_{\mathrm{s}}\right)+\nabla \cdot\left(\boldsymbol{k}_{\mathrm{sf}} \cdot \nabla\langle T\rangle_{\mathrm{f}}\right) \\
& -\frac{h_{\mathrm{sf}}}{\varepsilon_{\mathrm{s}}} \frac{A_{\mathrm{sf}}}{V_{0}}\left(\langle T\rangle_{\mathrm{s}}-\frac{\varepsilon_{\mathrm{s}}}{1-\varepsilon_{\mathrm{s}}}\langle T\rangle_{\mathrm{f}}\right)+\langle I\rangle_{\mathrm{s}}
\end{aligned}
$$

for the solid phase, and

$$
\begin{aligned}
& \varrho_{\mathrm{f}} c_{p, \mathrm{f}} \frac{\partial\langle T\rangle_{\mathrm{f}}}{\partial t}=\nabla \cdot\left(\boldsymbol{k}_{\mathrm{ff}} \cdot \nabla\langle T\rangle_{\mathrm{f}}\right)+\nabla \cdot\left(\boldsymbol{k}_{\mathrm{fs}} \cdot \nabla\langle T\rangle_{\mathrm{s}}\right) \\
& -\frac{h_{\mathrm{sf}}}{\varepsilon_{\mathrm{f}}} \frac{A_{\mathrm{sf}}}{V_{0}}\left(\langle T\rangle_{\mathrm{f}}-\frac{\varepsilon_{\mathrm{f}}}{1-\varepsilon_{\mathrm{f}}}\langle T\rangle_{\mathrm{s}}\right)+\langle I\rangle_{\mathrm{f}}
\end{aligned}
$$

for the fluid phase. The transport parameters $h_{\mathrm{sf}}$, $\boldsymbol{k}_{\mathrm{ss}, \mathrm{ff}, \mathrm{ff}, \mathrm{fs}}$ are introduced in (20), (21) that are, respectively, interphasial heat transfer coefficient, the solid phase and the fluid phase effective thermal conductivity tensors, and the solid-fluid phase coupled thermal conductivity tensors. These parameters can be determined from an analysis of the characteristic microscopic level temperature distributions in each phase within a representative elementary volume.

Wijngaarden and Westerterp [58] assumed heat transport to take place in a packed bed by three mechanisms: heat transfer from the solid to the gas, heat transfer through the gas, and heat transfer between gas and wall. Effective conductivity and heat transfer coefficients were determined by fitting the predicted temperatures to the measured temperature profiles. Thus, they achieved good agreement between measurements and predictions and, therefore, concluded that the series model is suited to be employed to packed beds.

Similarly, MacPhee and Dincer [59] investigated thermal energy storage system of ice capsules embedded in a liquid. During the charging process heat is retrieved from the ice capsules to cool the liquid, and thus, causing the ice inside the capsules to melt. Conversely, during discharge a liquid with a temperature below the melting point was in contact with the packed bed of ice capsules so that the ice capsules froze again, and thus, "stored the cold". The set of ice capsules is modelled as a continuous porous media, rather than the set of discrete particles.

Direct numerical simulation is increasingly applied to study heat transfer between two phases. Although it is considered to be the most accurate approach, it is very expensive in terms of computer resources and only a small area of the packed bed may be analysed nowadays. Lee et al. [60] predicted the flow in the core of a pebble bed reactor and its heat transfer. They have 
concluded that the results depend significantly on the modelling of the inter-pebble region, because the treatment of the contacts among the pebbles with approximated gaps may give inaccurate information about the local flow fields.

In general, bed reactors may be classified into the ordered packed bed reactors and randomly packed ones. The latter type is easier to implement and use, however, they experience much higher pressure drop and the overall heat transfer efficiency might be greatly reduced. Structured packing can reduce the pressure drop and improve the heat transfer performance. Simulations of the metal structured packed beds were reported in [61]. Their set-up consisted of a cylindrical arrangement of a number of axially parallel channels, discretised by a finite volume mesh. The flow medium was air treated as an ideal gas. It has been found that, at low Reynolds numbers, the heat transfer capability is mostly determined by the specific surface area, while at high Reynolds numbers, the property of solid phase and structure of void space is an important factor.

The effect of packing arrangement and particle shapes on flow and heat transfer inside the pores of different types of structured packed beds was studied numerically by Yang et al. [62]. The set-up consisted of 8 packed cells with symmetric boundary conditions. Spherical, flat ellipsoidal, and long ellipsoidal particles were used, which were arranged in simple cubic, body centre cubic, and face centre cubic lattices. The fluid flow inside the pores was described by three-dimensional NavierStokes and energy equations for steady incompressible flow. For Re $>300$, the RNG (renormalization group) $k-\varepsilon$ turbulence model and a scalable wall function were used. The flow in packed beds has been considered as flow in a porous media, where the macroscopic hydrodynamics is modelled by an extended ForchheimerDarcy approximation. It has been found that a proper selection of the packing form and the particle shape can significantly reduce the pressure drop in structured packed beds and improve the heat transfer performance.

The flow in an unstructured packing of poly-disperse spherical particles with a value of polydispersity deviating by $14 \%$ from the mean diameter was considered by Augier et al. [63]. A dense packing of spheres was generated using DEM, neglecting the friction between particles and between the particles and the walls. Drag coefficients and Nusselt numbers were calculated applying CFD for a single sphere and for two spheres located close to each other. These results were transformed to a packed bed in a column. In order to reduce computational efforts, two domains as a pie-shaped including the near-wall region and a region from the bulk far from the walls were extracted from the packed bed. The number of particles in these domains were 620 and 440, respectively. The hydrodynamics and heat transfer equations were solved in the range of Reynolds and Schmidt numbers of $1<\operatorname{Re}<100$ and $300<\mathrm{Sc}<1000$. The results have indicated that contraction of particles applied to the packing in order to enable finite-volume meshing leads to underestimation of the transverse dispersion.

Papadikis et al. [64] studied the heat transfer conditions dependent on the size of biomass particles exposed to a fluidised bed of sand and undergoing pyrolysis. The size of the sand particles was $400 \mu \mathrm{m}$, and the biomass particles of two size fractions, 350 and $550 \mu \mathrm{m}$, were used. Conductive heat transfer was considered for larger biomass particles, but was neglected for smaller biomass particles. The gas phase as a nitrogen gas was described by the Eulerian approach while the solid phase model was based on the radial distribution function and the granular temperature. Both phases were coupled through the particle drag force in the continuum and heat transfer along the particle radius by solving the heat diffusion equation for an isotropic particle. It has been found that different heat transfer mechanisms are involved for particles of different sizes, resulting in different heat transfer coefficients. The temperature gradients inside the particles could be neglected due to small Biot numbers. According to the study, smaller particles yield better results for fast pyrolysis applications, because they are better entrained in the bed during degradation. Smaller size reduced the effect of secondary reactions resulting in higher yields of bio-fuels.

Gamson et al. [65] studied heat, mass, and momentum transfer in the flow of gases through granular solids. Correlations were given for heat and mass transfer coefficients and pressure drop in the direction of the flow. They concluded that the heat transfer coefficient was independent of shape, interstitial configuration, and wetness of surfaces. The latter in conjunction with drying processes was also emphasised by Zahed and Singh [66], because heat transfer conditions determine the drying rate of packed beds. Barker [67] presented a review of heat transfer in packed beds. Correlations were given for heat transfer coefficients in particle packings, encountered in commercial set-ups, consisting of beds of randomly packed and ordered spheres and cylinders. Bowers and Reintjes [68] reviewed the literature concerning fluid particle heat transfer in packed and moving beds. Practical working equations for the solution 
of problems with some restrictions involving this type of heat transfer were developed. An extensive review of problems and models of fluid flow, heat and mass transfer in porous media may be found in Nithiarasu et al. [69], Swailes and Potts [6], Laguerre et al. [5], and Venugopal et al. [7].

\section{Discrete particle method}

Contrary to the continuum approach, the recently developed DPM considers a solid fuel particle as an individual entity with above-mentioned conversion and motion attached to it. Hence, the sum of all particle processes represents the entire process of a moving and fixed bed and may be summarised by the following formula:

\section{Entire Process $=$}

\section{$\sum$ Particle Processes + CFD .}

The approach includes three major processes as depicted in Fig. 1:

- particle conversion as an interaction process between the solid, liquid, and gaseous phases in a single particle (conversion module);

- particle ensemble motion, i. e., bed of particles in conjunction with their change of position (motion module);

- reacting flow in the void space between the particles in conjunction with heat and mass transfer between the particle surface and gas (CFD).

The above-mentioned computational aspects are dealt with individually in the motion and conversion module. The latter encompasses a large variety of chemo-physical processes such as drying, pyrolysis, devolatilization, gasification, or combustion in a packed or moving bed. Conversion of a particle is described by a set of one-dimensional and transient differential conservation equations including interactions such as heat transfer between neighbouring particles. The solution of these equations yields the distribution of temperature and species, e. g. carbon-dioxide or alkali salts, inside a particle versus time. Motion of particles in a rotary kiln or on a moving grate is derived from the discrete element method and describes the trajectory of each particle by solving Newton equations of motion [70-72]. Treatment of a flow of reacting gases in the voids is dealt with by well-established CFD tools.

The DPM uses object-oriented techniques that support objects representing three-dimensional particles of various shapes, size, and material properties. This makes DPM a highly versatile tool dealing with a large variety of different industrial applications of particulate materials.

Contrary to the continuum mechanics approach, the DPM considers a packed bed of solid fuel as composed of discrete particles with individual shapes and sizes. The conversion processes are described by transient and one-dimensional differential conservation equations for mass and energy with sufficient accuracy and applied to an individual particle. Chapman [73] states that in general elaborate models are required to gain a deeper insight into the complexity of solid fuel conversion [74-76] as employed in the current study. The onedimensional approach is supported by Man and Byeong [77], whereas the transient character is emphasized by Lee et al. [78, 79]. These requirements are met by the DPM and, therefore, offer a high degree of flexibility and detailed information. With the assumptions such as

- one-dimensional and transient behaviour,

- intrinsic rate modelling,

- particle geometry represented by slab, cylinder, or sphere,

- thermal equilibrium between gaseous, liquid, and solid phases inside the particle,

the differential conservation equations for energy, gaseous, and solid species $Y_{i}$ describe particle conversion:

$$
\begin{aligned}
& \frac{\partial\left(\rho c_{p} T\right)}{\partial t}=\frac{1}{r^{n}} \frac{\partial}{\partial r}\left(r^{n} \lambda_{\text {eff }} \frac{\partial T}{\partial r}\right)+\sum_{k=1}^{l} \dot{\omega}_{k} H_{k}, \\
& \frac{\partial Y_{i, \text { gas }}}{\partial t}=\frac{1}{r^{n}} \frac{\partial}{\partial r}\left(r^{n} D_{i} \frac{\partial Y_{i, \text { gas }}}{\partial r}\right)+\sum_{k=1}^{l} \dot{\omega}_{k, i, \text { gas }}, \\
& \frac{\partial Y_{i, \text { solid }}}{\partial t}=\sum_{k=1}^{l} \dot{\omega}_{k, i, \text { solid }},
\end{aligned}
$$

where $n$ defines the geometry of a cylinder $(n=1)$ or sphere $(n=2), \rho$ is the density, $c_{p}$ is the heat capacity at constant pressure. The locally varying heat conductivity $\lambda_{\text {eff }}$ is evaluated as [80]

$$
\lambda_{\text {eff }}=\epsilon_{P} \lambda_{g}+\eta \lambda_{\text {solid }}+(1-\eta) \lambda_{c}+\lambda_{\text {rad }},
$$

which takes into account heat transfer by conduction in the gas, solid, char, and radiation in the pore, respectively. The source term on the right-hand side of (22) 


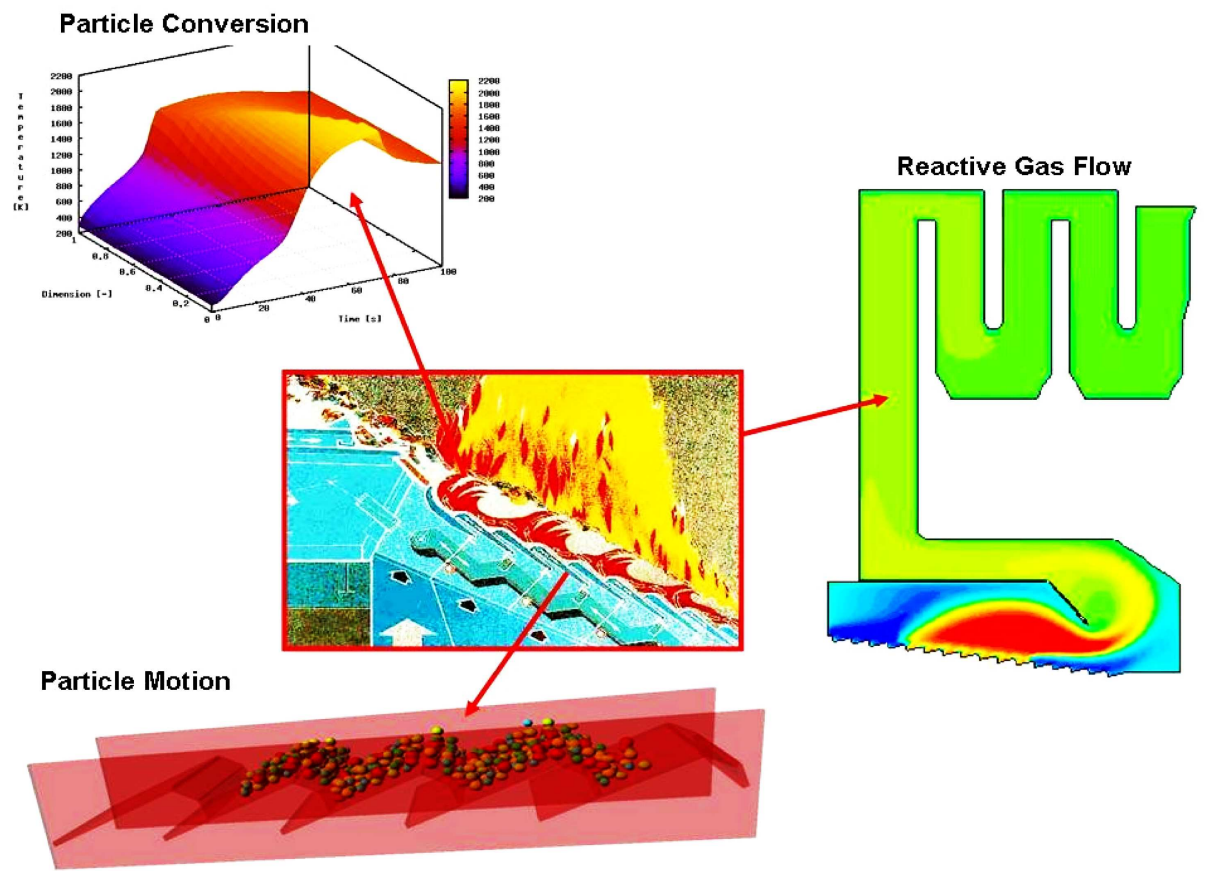

Fig. 1. Approach to solid fuel conversion of the discrete particle method (DPM).

represents heat release or consumption due to chemical reactions $k=1, \ldots, l$, with reaction rate $\dot{\omega}_{k}$ and enthalpy change $H_{k}$. The conservation equations for mass (23), (24) describe the time and spatially varying concentration $Y_{i}$ of species $i$ under the influence of reactive source terms, with reaction rate $\dot{\omega}_{k, i}$ for a species $i$ participating in reaction $k$, and diffusive transport. The latter is omitted for solid species. An effective diffusion coefficient $D_{i \text {,eff }}=D_{i} \epsilon_{P} / \tau$ with $\epsilon_{P}$ and $\tau$ being porosity and tortuosity is employed to describe the diffusive transport [81, 82].

\subsection{Initial and boundary conditions}

According to Kaume [83], the Nusselt number Nu for heat transfer of a sphere evaluates as

$$
\mathrm{Nu}=f \mathrm{Nu}_{\mathrm{m}, \text { sphere }}
$$

for a packed bed with $f$ and $\mathrm{Nu}_{\mathrm{m} \text {,sphere }}$ being an empirical correlation $f=1.0+1.5(1.0-\epsilon)$ and the mean Nusselt number for a spherical geometry, respectively. Under laminar conditions the latter is defined by

$$
\mathrm{Nu}_{\mathrm{m}, \text { sphere }}=2.0+0.664 \operatorname{Re}^{1 / 2} \operatorname{Pr}^{1 / 3},
$$

where Re and Pr denote the Reynolds and Prandlt numbers $(\operatorname{Pr} \sim 0.68$ [84]), respectively. Similarly, mass transfer is described by a Sherwood number $\mathrm{Sh}_{\mathrm{m} \text {,sphere }}$ [85]

$$
\mathrm{Sh}_{\mathrm{m}, \text { sphere }}=2.0+0.664 \mathrm{Re}^{1 / 2} \mathrm{Sc}^{1 / 3},
$$

where Sc is the Schmidt number. 9 Summarizing the previous section, the following boundary conditions for mass and heat transfer of a particle are applied:

$$
\begin{aligned}
-\left.\lambda_{\mathrm{eff}} \frac{\partial T}{\partial r}\right|_{R} & =\alpha\left(T_{R}-T_{\infty}\right)+\dot{q}_{\mathrm{cond}}+\dot{q}_{\mathrm{rad}}, \\
-\left.D_{i, \mathrm{eff}} \frac{\partial c_{i}}{\partial r}\right|_{R} & =\beta_{i}\left(c_{i, R}-c_{i, \infty}\right)
\end{aligned}
$$

where $T_{\infty}, c_{i, \infty}, \alpha$, and $\beta$ denote ambient gas temperature, concentration of species $i$, heat and mass transfer coefficients, respectively.

The conductive heat flux $\dot{q}_{\text {cond }}$ between two neighbouring particles in contact is estimated by

$$
\begin{aligned}
\dot{q}_{\text {cond }} & =-\frac{1}{1 / \lambda_{1}+1 / \lambda_{2}} \frac{\partial T}{\partial r} \\
& \approx-\frac{1}{1 / \lambda_{1}+1 / \lambda_{2}} \frac{T_{S, 1}-T_{S, 2}}{\Delta r_{S, 1}-\Delta r_{S, 2}},
\end{aligned}
$$

where the temperature gradient between two particles is approximated by the temperature difference between the outer shell values of the particles and the distance $\Delta r_{S, i}$ from the outer particle surface. The conductivities $\lambda_{1}$ and $\lambda_{2}$ refer to the particles in contact, respectively. The contact area $A_{\mathrm{c}}$ is assumed to be 
quadratic and determined by the contact angles $\gamma_{1}$ and $\gamma_{2}$,

$$
A_{\mathrm{c}}=\frac{1}{2}\left[\left(R_{1} \tan \gamma_{1}\right)^{2}+\left(R_{2} \tan \gamma_{2}\right)^{2}\right] .
$$

At higher temperatures, a particle $i$ emits a radiative flux at surface temperature $\left\langle T_{\mathrm{S}}\right\rangle$ and adsorbs a flux $\dot{q}_{\mathrm{rad}, j}$ from all neighbouring particles $j$ weighted by the respective view factor $F_{i \rightarrow j}$. Thus, the total flux due to radiation is given by

$$
\dot{q}_{\mathrm{rad}}=\sum_{j} F_{i \rightarrow j} \alpha \dot{q}_{\mathrm{rad}, j}-\epsilon \sigma\left\langle T_{S}\right\rangle^{4},
$$

where $\alpha$ and $\epsilon$ denote the adsorption and the emission coefficient, respectively. The view factor is determined as the ratio of the surface of particle $i$ to the sum of the surfaces of all neighbouring particles $j$ with

$$
F_{i \rightarrow j}=\frac{A_{i}}{\sum_{j} A_{j}} .
$$

For a detailed description of the DPM, the reader is referred to Peters [86].

\section{Results and discussion}

In a first step, the DPM is applied to predict heating of packed beds on fixed and moving grates. This particular set-up was chosen to examine the influence of bed motion on the temperature distribution. This requires solution of the energy equation for each particle, taking into account conduction and radiation between particles and convective heat transfer between the particles and the surrounding flow field. Particles were approximated by a spherical geometry of different sizes, and the material was represented by a fir wood. The packed bed was exposed to a constant radiative flux from above. In order to exclude the effect of a locally varying convective heat transfer of the gas phase in the voids of a packed bed, gas temperature, which is used as the ambient temperature for the particles in the model, and heat transfer coefficient were kept constant.

For simulation, the packed bed consisted of 300 spherical particles with diameters randomly distributed in the range from 8 to $16 \mathrm{~mm}$. The initial particle temperature was set to $400 \mathrm{~K}$. The ambient fluid temperature was kept constant at $300 \mathrm{~K}$ for all the simulation time. Flux of radiation from the top wall was set to $30 \mathrm{~kW} / \mathrm{m}^{2}$, and the heat transfer coefficients were defined as $\alpha=20.0$. Conversion of the packed bed was evaluated every $1 \mathrm{~s}$, while particle positions were calculated at every time step $\Delta t=10^{-5} \mathrm{~s}$ of time integration
Table 1. Mechanical properties of the packed bed particles.

\begin{tabular}{ll}
\hline Property & Value \\
\hline Density & $610 \mathrm{~kg} / \mathrm{m}^{3}$ \\
Young (elastic) modulus & $50 \mathrm{MPa}$ \\
Shear modulus & $15 \mathrm{MPa}$ \\
Poisson modulus & 0.2 \\
Dynamic friction coefficient & 0.8 \\
Normal dissipation coefficient & $100 \mathrm{~s}^{-1}$ \\
Shear dissipation coefficient & $100 \mathrm{~s}^{-1}$ \\
\hline
\end{tabular}

of particle motion equations. Number of cells for resolution of particle discretization was equal to 11. Two problems were simulated: first, a packed bed on a fixed grate, and the second problem was defined for moving grate, with its bars moving with period $T_{\mathrm{B}}=10 \mathrm{~s}$ and amplitude $A_{\mathrm{B}}=0.1238 \mathrm{~m}$. Mechanical properties of the particles are summarized in Table 1 .

\subsection{Temperature distribution in a fixed bed}

As mentioned above, in a first step the particles were distributed on the grate bars until they came to a rest. This arrangement of particles was also used as initial conditions to predict the temperature distribution of a moving bed. Thus, transport of heat inside the bed was due to conduction and radiation between particles, whereby the latter contributes significantly at higher temperatures only. The results obtained from a prediction with the DPM at times $t$ of 75, 150, 450, and $600 \mathrm{~s}$ are shown in Fig. 2(a-d). Due to a radiative flux from above onto the surface of the packed bed, particles on the surface heat up fastest. Therefore, generally heat is transported downward into the packed bed yielding an approximate layered distribution of temperature with lowest temperatures near the grate bars depicted in Fig. 2(a).

However, as time proceeds, the layered distribution of temperature is disturbed by transverse temperature gradients shown in Fig. 2(b, c), so that the temperature gradients also occur along the grate bars. Predominantly at the tip regions of the grate bars on the surface of the packed bed particles heat up at a faster rate and, therefore, experience higher temperatures than remaining particles between the tip regions. Due to the arrangement of the particles as a granular material in the frontal edge regions of the bars, the coordination number, i. e. number of the nearest neighbours of those particles, is lower than in other regions of the packed bed. Therefore, the heat transfer to neighbours due to both conduction and radiation is lower than for particles with higher coordination number. Hence, these particles experience a higher temperature due to less heat losses to 


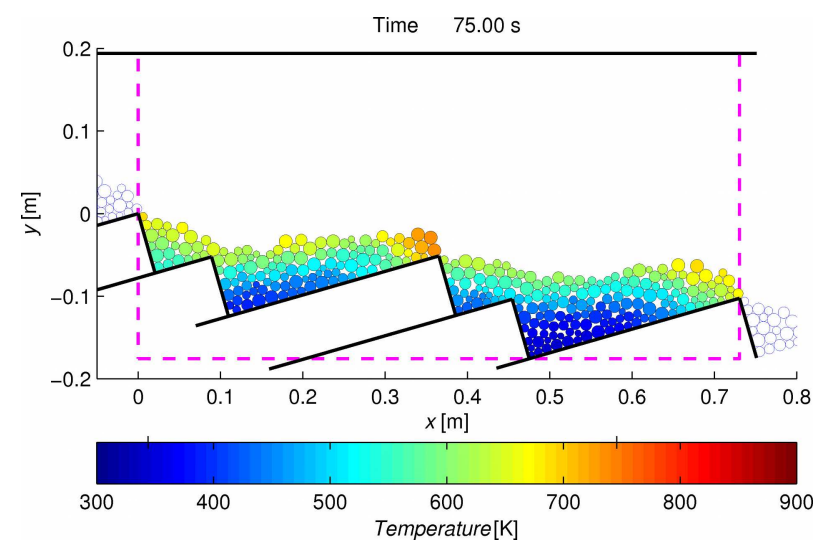

(a)

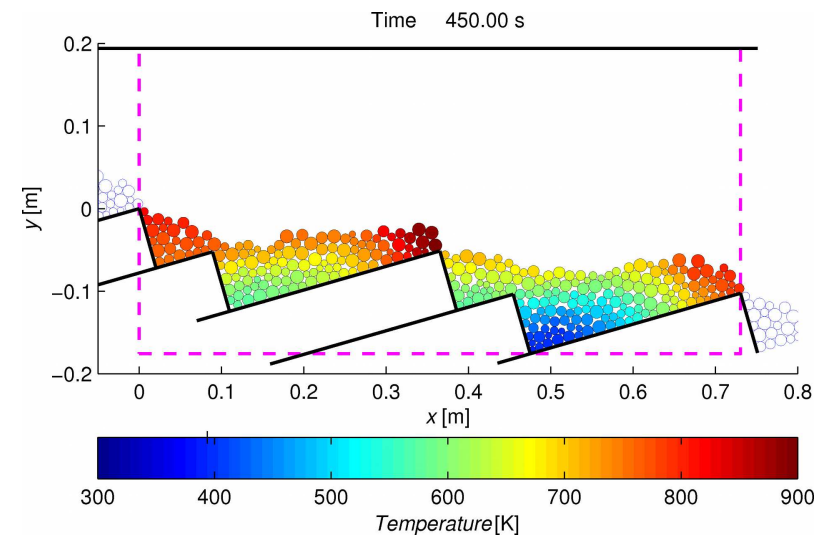

(c)

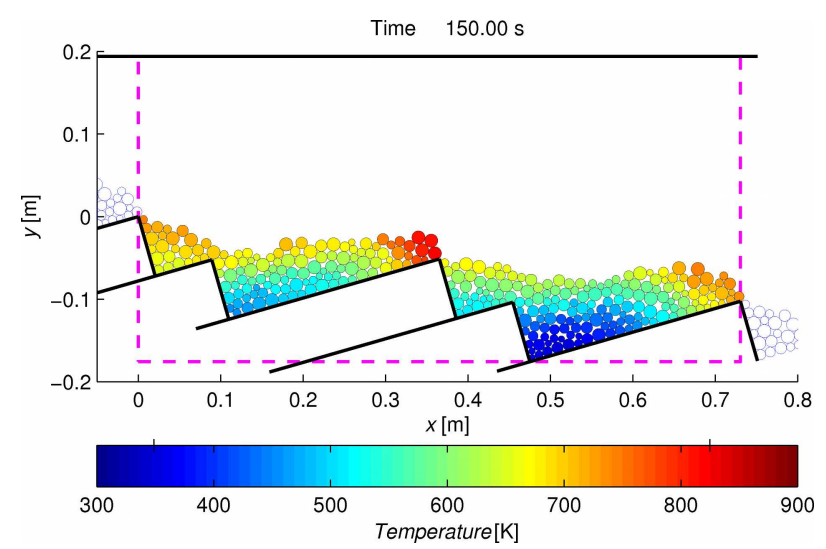

(b)

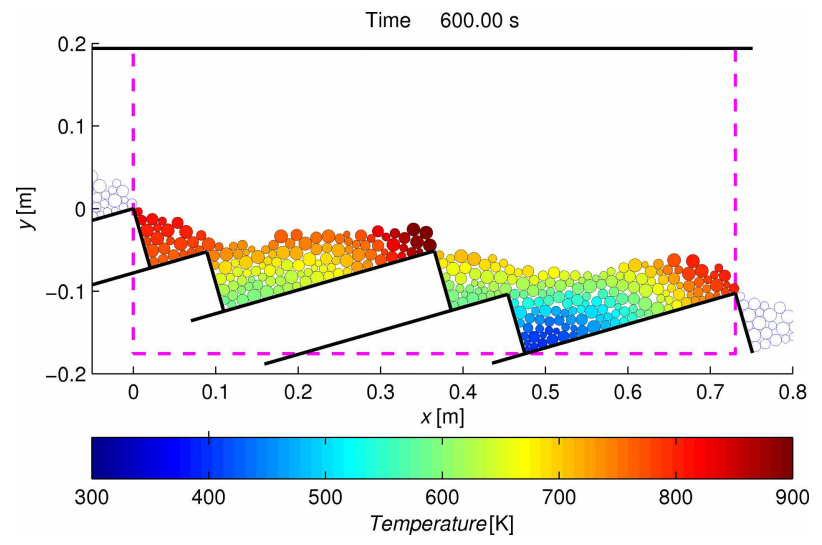

(d)

Fig. 2. Temperature distribution of resting particles in a fixed bed subject to a radiative flux of $\dot{q}^{\prime \prime}=30.0 \mathrm{~kW} / \mathrm{m}^{2}$ on a forward acting grate at different time moments: (a) $t=75 \mathrm{~s}$, (b) $t=150 \mathrm{~s}$, (c) $t=450 \mathrm{~s}$, (d) $t=600 \mathrm{~s}$.

neighbouring particles. These conditions are difficult, if possible at all, to represent by a continuous mechanics approach for a packed bed. As seen by comparing Fig. 2(c) and (d), stationary values of particle temperatures are achieved in the packed bed after a certain time period.

\subsection{Temperature distribution in a moving bed}

In order to reduce simulation time, only part of the entire grate was taken and periodic boundary conditions were employed at the entry and exit of the grate. Particles leaving the grate at the exit area were periodically introduced at the entry of the grate, and thus, reflecting a sequence of grate sections.

A periodic forward and backward motion scheme was applied to every second grate bar, so that bars between the moving bars were kept at rest. These kinetics representing the operation mode of a forward acting grate cause the particles to move over the grate through the combustion chamber. Velocity and periodicity of the bar motion effects the residence time of the parti- cles to a large extent [87]. The predictions were carried out under the same conditions as for the resting particles with the difference that the packed bed was taken as a moving bed. Its predictions for the temperature distribution of the particles at times $t$ of 75, 150, 450, and $600 \mathrm{~s}$ is shown in Fig. $3(\mathrm{a}-\mathrm{d})$.

Although a layered temperature distribution develops during heat-up of the moving bed, transverse temperature gradients disappeared due to moving particles. Moving beds represent a system with high dynamics, so that particles change both their neighbours and coordination number. This leads to a varying amounts of heat transferred between particles. Additionally, initial surface particles do not remain at surface during the entire transport over the grate. Thus, particles are almost randomly exposed to surface radiation for a certain period. These mechanisms contribute to a more homogeneous temperature distribution of the moving bed. Similarly to the case of fixed grate, a stationary temperature distribution is attained after a certain period of time in the packed bed on the moving grate as well (Fig. $3(\mathrm{c}, \mathrm{d})$ ). 


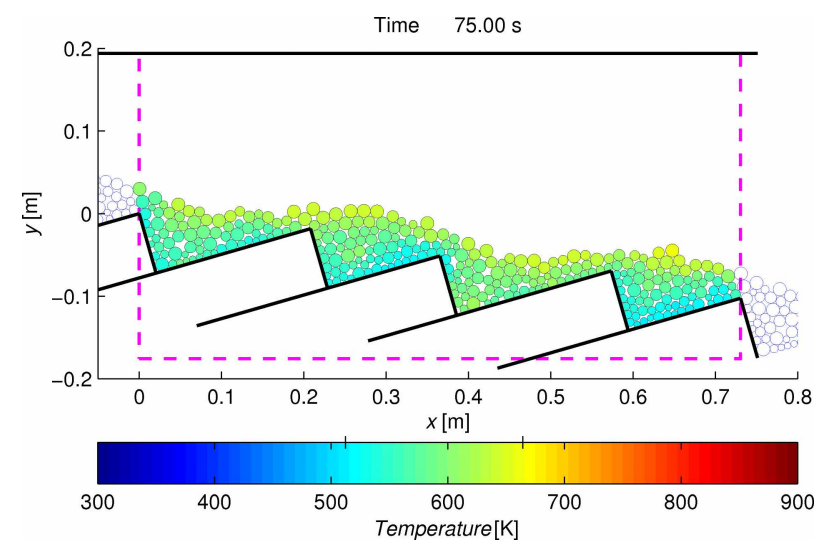

(a)

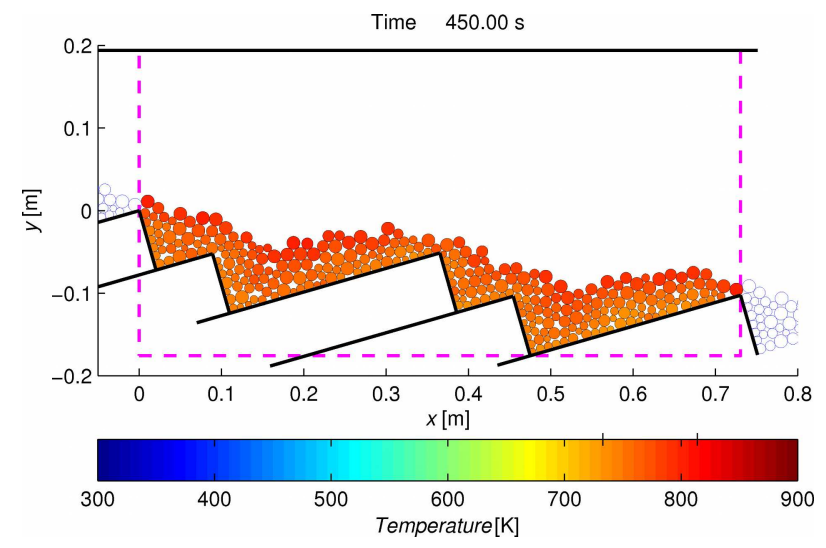

(c)

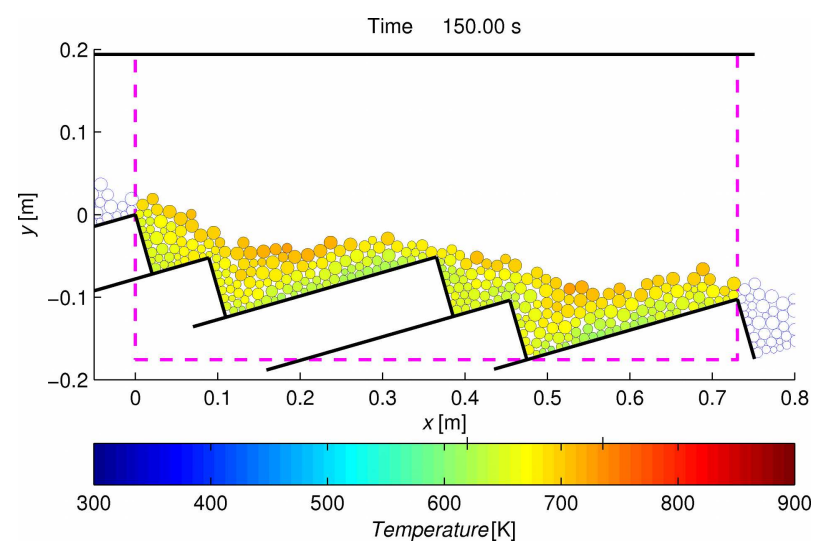

(b)

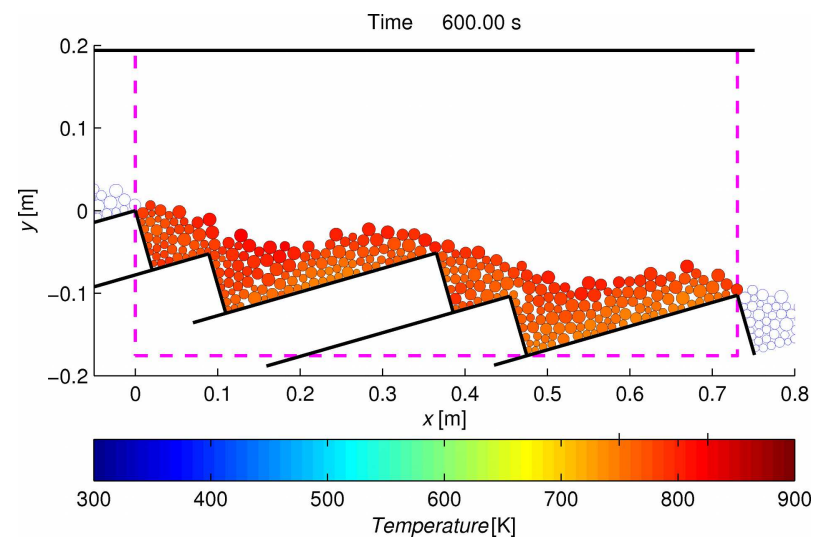

(d)

Fig. 3. Temperature distribution of particles in a moving bed subject to a radiative flux of $\dot{q}^{\prime \prime}=30.0 \mathrm{~kW} / \mathrm{m}^{2}$ on a forward acting grate at different time moments: (a) $t=75 \mathrm{~s}$, (b) $t=150 \mathrm{~s}$, (c) $t=450 \mathrm{~s}$, (d) $t=600 \mathrm{~s}$.

\section{Summary and conclusions}

We have reviewed different computational approaches to modelling heat transfer in packed beds of discrete particles. Heat-up of both the fixed and moving beds of fir wood particles was investigated numerically by the discrete particle method (DPM). The latter describes the temperature distribution of particles by solving the transient and one-dimensional differential conservation equation for energy. Spherical particles of different sizes were arranged on a forward acting grate and a constant radiative flux was employed onto the surface of the bed. Heat transfer within the packed bed was taken into account by conduction and radiation between neighbouring particles. In order to emphasise the effect of bed motion, temperatures of the packed bed were predicted under motionless and moving grate conditions. The former simulation mode yielded a layered temperature distribution versus the height of the packed bed with high temperature regions predominantly occurring near the front edge of the grate bars due to a reduced coordination number of particles in this area. Motion of a packed bed on a forward acting grate reduces tempera- ture gradients due to periodically changing surface particles and a varying number of neighbours versus time and space.

\section{References}

[1] E. Smirnov, A. Muzykantov, V. Kuzmin, A. Kronberg, and I. Zolotarskii, Radial heat transfer in packed beds of spheres, cylinders and Rashig rings: Verification of model with a linear variation of $\lambda_{e r}$ in the vicinity of the wall, Chem. Eng. J. 91, 243-248 (2003).

[2] E.I. Smirnov, V.A. Kuzmin, and I.A. Zolotarskii, Radial thermal conductivity in cylindrical beds packed by shaped particles, Chem. Eng. Res. Des. 82(A2), 293296 (2004).

[3] I. Figueroa, W.L. Vargas, and J.J. McCarthy, Mixing and heat conduction in rotating tumblers, Chem. Eng. Sci. 65, 1045-1054 (2010).

[4] O. Laguerre, S.B. Amara, G. Alvarez, and D. Flick, Transient heat transfer by free convection in a packed bed of spheres: Comparison between two modelling approaches and experimental results, Appl. Therm. Eng. 28, 14-24 (2008). 
[5] O. Laguerre, S.B. Amara, and D. Flick, Heat transfer between wall and packed bed crossed by low velocity airflow, Appl. Therm. Eng. 26, 1951-1960 (2006).

[6] D.C. Swailes and I. Potts, Transient heat transport in gas flow through granular porous media, Transp. Porous Media 65, 133-157 (2006).

[7] G. Venugopal, C. Balaji, and S. Venkateshan, Experimental study of mixed convection heat transfer in a vertical duct filled with metallic porous structures, Int. J. Therm. Sci. 49, 340-348 (2010).

[8] C.L. Tien, Thermal radiation in packed and fluidized beds, Trans. ASME J. Heat Transfer 110, 1230-1242 (1988).

[9] S. Manickavasagam and M.P. Menguc, Effective optical properties of pulverized coal particles determined from FT-IR spectrometer experiments, Energ. Fuel. 7, 860-869 (1993).

[10] S.C. Mishra and M. Prasad, Radiative heat transfer in participating media - A review, Sādhanā 23(2), 213232 (1998).

[11] M. Kaviany and B.P. Singh, Radiative heat transfer in packed beds, in: Heat \& Mass Transfer in Porous Media, eds. M. Quintard and M. Todorovic (Elsevier Pub. Corp., Amsterdam, 1992) pp. 191-202.

[12] J. Thoméo and J.R. Grace, Heat transfer in packed beds: experimental evaluation of one-phase water flow, Braz. J. Chem. Eng. 21(1), 13-22 (2004).

[13] M.A. Fanaei and B.M. Vaziri, Modeling of temperature gradients in packed-bed solid-state bioreactors, Chem. Eng. Process. 48, 446-451 (2009).

[14] M.F.P. Moreira, M. do Carmo Ferreira, and J.T. Freire, Evaluation of pseudohomogeneous models for heat transfer in packed beds with gas flow and gas-liquid cocurrent downflow and upflow, Chem. Eng. Sci. 61, 2056-2068 (2006).

[15] P. Zehner, Experimentelle und theoretische Bestimmung der effektiven Wärmeleitfähigkeit durchströmter Kugelschüttungen bei mäßigen und hohen Temperaturen, VDI-Forschungsheft 558, 35 (1973) [in German].

[16] F.W. Hennecke and E.U. Schlünder, Heat transfer in heated or cooled tuba with packings of spheres, cylinders and Raschig rings, Chem. Ing. Tech. 45(5), 277284 (1973).

[17] P. Zehner and E.U. Schlünder, Effective thermal conductivity of spherical packings perfused at moderate and high temperatures, Chem. Ing. Tech. 45(5), 272276 (1973).

[18] J.J. Lerou and G.F. Froment, Estimation of heat transfer parameters in packed beds from radial temperature profiles, Chem. Eng. J. (Lausanne) 15(3), 233-237 (1978).

[19] R. Bauer, Effective radial thermal conductivity of gaspermeated packed beds containing particles of different shape and size distribution, VDI Forschungsh. 582, 39 (1977).
[20] A.G. Dixon and D.L. Cresswell, Theoretical prediction of effective heat transport parameters in packed beds, AIChE J. 25(4), 663-676 (1979).

[21] H. Hofmann, Fortschritte bei der Modellierung von Festbettreaktoren, Chem. Ing. Tech. 45(5), 257-265 (1979).

[22] T. Wellauer, D.L. Cresswell, and E.L. Newson, Heat transfer in packed bed reactor tubes suitable for selective oxidation, in: Chemical Reaction EngineeringBoston, ACS Symp. Ser. 196 (American Chemical Society, 1982) pp. 527-543.

[23] K.R. Westerterp, W.P.M. van Swaaii, and A.A.C.M. Beenackers, Chemical Reactor Design and Operation, 2nd ed. (Wiley, Chichester, 1987).

[24] E. Tsotsas and H. Martin, Thermal conductivity of packed beds: A review, Chem. Eng. Process. 22, 19-37 (1987).

[25] A.F. Regin, S. Solanki, and J. Saini, An analysis of a packed bed latent heat thermal energy storage system using PCM capsules: Numerical investigation, Renew. Energ. 34, 1765-1773 (2009).

[26] S.M.A.G. Ulson de Souza and S. Whitaker, Mass transfer in porous media with heterogeneous chemical reaction, Braz. J. Chem. Eng. 20(2) (2003).

[27] S. Whitaker, Transport Processes with Heterogeneous Reaction, in: Concepts and Design of Chemical Reactors, Chemical Engineering: Concepts and Reviews Vol. 3, eds. S. Whitaker and A.E. Cassano (Gordon and Breach, New York, 1986).

[28] S. Whitaker, Volume Averaging of Transport Equations, in: Fluid Transport in Porous Media, Advances in Fluid Mechanics Vol. 13, ed. J.P. Du Plessis (Computational Mechanics Publications, Southampton, UK, 1997).

[29] S. Whitaker, The Method of Volume Averaging, Theory and Application of Transport in Porous Media Vol. 13 (Kluwer Academic, London, 1999).

[30] M. Quintard and S. Whitaker, Transport in ordered and disordered porous media I: The cellular average and the use of weighting functions, Transport Porous Media 14, 163-177 (1994).

[31] M. Quintard and S. Whitaker, Transport in ordered and disordered porous media II: Generalized volume averaging, Transport Porous Media 14, 179-206 (1994).

[32] M. Quintard and S. Whitaker, Transport in ordered and disordered porous media III: Closure and comparison between theory and experiment, Transport Porous Media 15, 31-49 (1994).

[33] M. Quintard and S. Whitaker, Transport in ordered and disordered porous media IV: Computer generated porous media, Transport Porous Media, 15, 51-70 (1994).

[34] M. Quintard and S. Whitaker, Transport in ordered and disordered porous media V: Geometrical results for two-dimensional systems, Transport Porous Media 15, 183-196 (1994). 
[35] A.L. Negrini, A. Fuelber, J. Freire, and J. Thoméo, Fluid dynamics of air in a packed bed: velocity profiles and the continuum model assumption, Braz. J. Chem. Eng. 16(4) (1999).

[36] R.W. Fahien and I.M. Stankovic, An equation for the velocity profile in packed columns, Chem. Eng. Sci. 34, 1350 (1979).

[37] C.E. Schwartz and J.M. Smith, Flow distribution in packed beds, Ind. Eng. Chem. 45(6), 1209 (1953).

[38] D. Vortmeyer and J. Schuster, Evaluation of steady flow profiles in rectangular and circular packed beds by a variational method, Chem. Eng. Sci. 38(10), 1691 (1983).

[39] G.E. Mueller, Prediction of radial porosity distribution in randomly packed fixed beds of uniformly sized spheres in cylindrical containers, Chem. Eng. Sci. 46(2), 706 (1991).

[40] R.F. Benenati and C.B. Brosilow, Void fraction distribution in beds of spheres, AIChE J. 8(3), 359 (1962).

[41] D.P. Haughey and G. Beveridge, Local voidage variation in a randomly packed bed of equal-sized spheres, Chem. Eng. Sci. 21, 905 (1966).

[42] F.M.Z. Zotin, The Wall Effect in Packed Beds, Master's thesis, Universidade Federal de Sao Carlos, Sao Carlos (1985).

[43] V.M.H. Govindarao and G.F. Froment, Voidage profiles in packed beds of spheres, Chem. Eng. Sci. 41, 533 (1986).

[44] A.G. Dixon, Correlations for wall and particle shape effects on fixed-bed bulk voidage, Can. J. Chem. Eng. 66, 705 (1988).

[45] F.M.Z. Zotin, The packing of spheres in a cylindrical container: the thickness effect, Chem. Eng. Sci. 50(9), 1504 (1995).

[46] M. Winterberg, E. Tsotas, A. Krischke, and D. Vortmeyer, A simple and coherent set of coefficients for modelling of heat and mass transport with and without chemical reaction in tubes filled with spheres, Chem. Eng. Sci. 55, 967-979 (2000).

[47] M. Giese, Strömung in porösen Medien unter Berücksuchtigung effectiver Viskositäten, Ph.D. thesis, TU München, Germany (1998).

[48] M. Giese, K. Rottschädel, and D. Vortmeyer, Measured and modelled superficial flow profiles in packed beds with liquid flow, AIChE J. 44(2), 484-490 (1998).

[49] W. Liu, S.W. Peng, and K. Mizukami, A general methematical modelling for the heat and mass transfer in unsaturated porous media. An application to free evaporative cooling, Heat Mass Tran. 31, 49-55 (1995).

[50] D. Vortmeyer, Mathematical modelling of reactionand transferprocesses in the flow through packed beds taking in account non-homogeneous flow distribution, Wärme- und Stoffübertragung 21, 247-257 (1987).

[51] S. Polesek-Karczewska, Effective thermal conductivity of packed beds of spheres in transient heat transfer, Heat Mass Tran. 39, 375-380 (2003).
[52] D. Vortmeyer, Axial heat dispersion in packed beds, Chem. Eng. Sci. 30, 999-1001 (1975).

[53] E.U. Schlünder, Equivalence of one- and two-phase models for heat transfer processes in packed beds: one-dimensional theory, Chem. Eng. Sci. 30, 449-452 (1975).

[54] G.F. Froment and K.B. Bischoff, Chemical Reactor Analysis and Design (John Wiley \& Sons, 1979).

[55] S.I. Duarte, O.A. Ferretti and N.O. Lemcoff, A heterogeneous one-dimensional model for non-adiabatic fixed bed catalytic reactors, Chem. Eng. Sci. 30, 10251031 (1984).

[56] G.C. Glatzmaier and W.F. Ramirez, Use of volume averaging for the modelling of thermal properties of porous materials, Chem. Eng. Sci. 30, 3157-3169 (1988).

[57] J.G. Fourie and J.P. Du Plessis, A two-equation model for heat conduction in porous media, Transport Porous Media 53, 145-161 (2003).

[58] R.J. Wijngaarden and K.R. Westerterp, A heterogeneous model for heat transfer in packed beds, Chem. Eng. Sci. 48, 1273-1280 (1993).

[59] D. MacPhee and I. Dincer, Thermal modeling of a packed bed thermal energy storage system during charging, Appl. Therm. Eng. 29, 695-705 (2009).

[60] J.J. Lee, G.C. Park, K.Y. Kim, and W.J. Lee, Numerical treatment of pebble contact in the flow and heat transfer analysis of a pebble bed reactor core, Nucl. Eng. Des. 237, 2183-2196 (2007).

[61] H. Mei, C. Li, and H. Liu, Simulation of heat transfer and hydrodynamics for metal structured packed bed, Catal. Today 105, 689-696 (2005).

[62] J. Yang, Q. Wang, M. Zeng, and A. Nakayama, Computational study of forced convective heat transfer in structured packed beds with spherical or ellipsoidal particles, Chem. Eng. Sci. 65, 726-738 (2010).

[63] F. Augier, F. Idoux, and J. Delenne, Numerical simulations of transfer and transport properties inside packed beds of spherical particles, Chem. Eng. Sci. 65, 10551064 (2010).

[64] K. Papadikis, S. Gu, and A.V. Bridgewater, Computational modelling of the impact of particle size to the heat transfer coefficient between biomass particles and a fluidised bed, Fuel Process. Techn. 91, 68-79 (2010).

[65] B.W. Gamson, G. Thodos, and O.A. Hougen, Heat, mass and momentum transfer in the flow of gases through granular solids, Trans. Am. Inst. Eng. 39(1), 135 (1943).

[66] A. Zahed and R. Singh, Convective heat transfer coefficient in a packed bed of rice, JKAU Eng. Sci. 1, 11 -20 (1989).

[67] J. Barker, Heat transfer in packed beds, Ind. Eng. Chem. 57(4), 43-51 (1965).

[68] T.G. Bowers and H. Reintjes, A review of fluid-toparticle heat transfer in packed and moving beds, Chem. Eng. Progr. Symp. 57(32), 69-74 (1961). 
[69] P. Nithiarasu, K. Seetharamu, and T. Sundararajan, Finite element modelling of flow, heat and mass transfer in fluid saturated porous media, Arch. Comput. Meth. Eng. 9(1), 3-42 (2002).

[70] A. Džiugys and B. Peters, An approach to simulate the motion of spherical and non-spherical fuel particles in combustion chambers, Granular Matter 3(4), 231-266 (2001).

[71] A. Džiugys and R. Navakas, The role of friction on size segregation of granular material, Mechanika No. 4(66), 59-68 (2007).

[72] A. Džiugys and R. Navakas, The role of friction in mixing and segregation of granular material, Granular Matter 11(6), 403-416 (2009).

[73] P. Chapman, CFD enhances waste combustion design and modification, in: Combustion Canada '96, Ottawa, Ontario, Canada, June 5-7, 1996.

[74] E. Specht, Kinetik der Abbaureaktionen, Habilitationsschrift, TU Clausthal-Zellerfeld (1993).

[75] N.M. Laurendeau, Heterogeneous kinetics of coal char gasification and combustion, Progr. Energ. Combust. Sci. 4, 221 (1978).

[76] M.A. Elliott, in: Chemistry of Coal Utilization, Suppl. Vol. 2, Ch. Fundamentals of Coal Combustion (Wiley, New York, 1981) p. 1153.

[77] Y.H. Man and R.C. Byeong, A numerical study on the combustion of a single carbon particle entrained in a steady flow, Combust. Flame 97, 1-16 (1994).

[78] J.C. Lee, R.A. Yetter, and F.L. Dryer, Transient numerical modelling of carbon ignition and oxidation, Combust. Flame 101, 387-398 (1995).

[79] J.C. Lee, R.A. Yetter and F.L. Dryer, Numerical simulation of laser ignition of an isolated carbon particle in quiescent environment, Combust. Flame 105, 591-599 (1996).

[80] M. Grønli, A Theoretical and Experimental Study of the Thermal Degradation of Biomass, Ph.D. thesis, The Norwegian University of Science and Technology Trondheim (1996).

[81] Shih-I Pai, Two-Phase Flows, Vieweg Tracts in Pure and Applied Physics (Braunschweig, 1977).

[82] F.A.L. Dullien, Porous Media: Fluid Transport and Pore Structure (Academic Press, San Diego, 1979).

[83] M. Kraume, Transportvorgänge in der Verfahrenstechnik (Springer, 2003).

[84] D. Hänel, Molekulare Gasdynamik (Springer, 2004).

[85] A. Schönbucher, Thermische Verfahrenstechnik (Springer, 2002).

[86] B. Peters, Thermal Conversion of Solid Fuels (WIT Press, Southampton, 2003).

[87] B. Peters, A. Džiugys, H. Hunsinger, and L. Krebs, An approach to qualify the intensity of mixing on a forward acting grate, Chem. Eng. Sci. 60(6), 1649-1659(2005).

\title{
KIETOJO KURO ŠILUMINIŲ VIRSMŲ MODELIAVIMAS TAIKANT DISKREČIŲJŲ DALELIŲ METODĄ
}

\author{
B. Peters ${ }^{a}$, A. Džiugys ${ }^{b}$, R. Navakas ${ }^{b}$ \\ ${ }^{a}$ Liuksemburgo universitetas, Liuksemburgas \\ ${ }^{\mathrm{b}}$ Lietuvos energetikos institutas, Kaunas, Lietuva
}

\section{Santrauka}

Aprašytas diskrečiụjų dalelių metodas (DPM), pagrịstas diskrečiųjų elementų metodu. Tai yra pažangus skaitinio modeliavimo irankis, leidžiantis atsižvelgti i granuliuotos terpès, pvz., anglių ar biomasès, judèjimą ir cheminius virsmus krosnyse, apimantis ir skaitinę fluidų dinamiką. Taip pat galimas atskiru procesų - mechaninio judèjimo arba cheminių virsmu - modeliavimas. Diskre- čiujų dalelių metode pritaikomi objektinio programavimo principai, vaizduojant i̇vairių formų, dydžių ir medžiagos savybių trimates daleles. Tai leidžia modeli plačiai taikyti įvairiose pramonès srityse, susijusiose su granuliuotų medžiagu panaudojimu. Pateikta literatūros, susijusios su masès ir šilumos virsmų granuliuotose terpèse modeliavimu, apžvalga. 